\title{
Programas de pós-graduação: um espaço para discussões críticas sobre a formação e o exercício profissional do jornalista
}

\section{Graduate programs: a space for critical discussions about the formation and work of the professional journalist}

\section{Los programas de posgrado: un espacio para los debates críticos sobre la formación y ejercicio profesional del periodista}

Cristiane Hengler Corrêa Bernardo, doutora em Educação pela Universidade Federal do Mato Grosso do Sul (UFMS) e professora assistente doutora da Universidade Estadual Paulista Júlio de Mesquita Filho (Unesp) - Campus de Tupã. E-mail: cristiane@ tupa.unesp.br .

\section{Resumo}

0 presente texto objetiva estabelecer um debate acerca da pós-graduação em Jornalismo, entendendo-a como um caminho para a qualidade da formação do jornalista diante da não obrigatoriedade do diploma de graduação para o exercício profissional. Para que tal debate encontrasse argumentos que o amparassem, baseou-se o artigo em alguns pontos da reconstrução histórica da profissão, assim como levantou iniciativas realizadas pelos vários organismos que têm se dedicado a refletir sobre a formação do jornalista e suas práticas profissionais.

Palavras-chave: Pós-Graduação. Jornalismo. Ensino de Jornalismo. Comunicação Social. 


\section{Abstract}

This article aims to establish a debate about graduate study in journalism, understanding it as a way to assure quality training, considering that an undergraduate degree in journalism is not mandatory for professional practice. In order to provide supporting arguments for the debate, this article addresses aspects of the profession's historical reconstruction, as well as initiatives promoted by several organizations involving reflections on the training and professional practices of the journalist.

Keywords: Graduate Study. Journalism. Journalism Teaching. Social Communication.

\section{Resumen}

El presente texto tiene como objetivo establecer un debate sobre el posgrado en periodismo, entendiéndola como un camino hacia la calidad de la formación del periodista ante la no obligatoriedad de la graduación para el ejercicio profesional. Para que esta discusión encontrara argumentos que la apoyara, el artículo se basó en algunos puntos de la reconstrucción histórica de la profesión, así como suscitó las iniciativas emprendidas por los diversos organismos que se han dedicado en la reflexión sobre la formación del periodista y sus prácticas profesionales.

Palabras clave: Posgraduado. Periodismo. La enseñanza del Periodismo. La Comunicación Social.

\section{Introdução}

O término da obrigatoriedade do diploma para o exercício da profissão de jornalista, votado e aprovado no dia 17 de julho de 2009 pelo Supremo Tribunal Federal (STJ), suscita inúmeras discussões acerca da formação acadêmica do jornalista. Debates esses que são importantes desde que versem sobre a qualidade dessa formação e não somente 
sobre a sua obrigatoriedade ou não. Consumado o fato, mesmo que venha a ser revogado, não se pode mais perder tempo com uma reflexão centrada apenas na exigência do diploma, e não na sua qualidade.

Foi exatamente com base na ausência de qualidade dos cursos de Comunicação Social com habilitação em Jornalismo que representantes da imprensa brasileira conseguiram apoio para abolir o diploma. A defesa ganhou força na própria Constituição da República Federativa do Brasil de 1988, por meio do Capítulo V, Da Comunicação Social, art. 220, cujo conteúdo prevê que "[...] a manifestação do pensamento, a criação, a expressão e a informação, sob qualquer forma, processo ou veículo não sofrerão qualquer restrição, observado o disposto nesta Constituição".

No que tange à liberdade de expressão, sua garantia constitucional, com base em ideais neoliberais, pode ser considerada uma das grandes aliadas no sentido de testemunhar contra a obrigatoriedade do diploma para o jornalista, uma vez que o principal argumento utilizado contra essa exigência é o de que ela fere esse princípio básico do cidadão.

De acordo com Battezzati (2006, p. 17), para os empresários do ramo, os cursos de Comunicação não preparavam profissionais habilitados com competência e conhecimento técnico para atuar no mercado: “Eles entendiam que a universidade não estava preocupada com as mudanças ocorridas na sociedade e, quando os diplomados enfrentavam o mercado, se deparavam com uma realidade totalmente diferente daquela apresentada nas escolas de comunicação”. Porém, devido aos objetivos políticos contidos nas reformas, esses últimos não foram ouvidos em suas argumentações.

Não se considera que os proprietários dos veículos da comunicação, conceituados neste artigo como donos da produção, estivessem corretos com relação ao que entendiam como qualidade dessa formação, uma vez que seu interesse era o de qualificar para domínio dos meios de produção, atendendo, assim, aos objetivos da imprensa capitalista. 


\section{A não obrigatoriedade do diploma encontra ressonância na história do País}

É importante ainda ressaltar neste momento que, apesar de o STJ ter aprovado a não obrigatoriedade do diploma em 2009, muitas iniciativas ainda são empreendidas no sentido de retomar tal obrigatoriedade para o exercício profissional do jornalismo. Duas delas, que ainda se encontram em tramitação, são oriundas do Senado Federal e da Câmara dos Deputados. No mês de novembro de 2013, a Comissão de Constituição e Justiça e de Cidadania (CCJC) da Câmara dos Deputados aprovou a admissibilidade da Proposta de Emenda à Constituição (PEC) n 206, de 2012, apresentada pelo Senado, que torna novamente obrigatória a exigência do diploma. Os próximos passos são a formação de uma comissão especial para analisar a emenda, que, se aprovada, será encaminhada para o plenário e votada em dois turnos.

Torna-se fundamental também pontuar outra iniciativa ainda em trâmite: a PEC $n^{\circ}$ 386, de 2009, da Câmara, que restabelece a obrigatoriedade de curso superior específico para o jornalista. Tal proposta, aprovada por comissão especial no mês de julho de 2010, ainda não teve sua inclusão na pauta do Plenário.

Todavia, discutir a não obrigatoriedade do diploma não é o objetivo deste artigo. O objetivo central do presente estudo é o de discutir a importância que a pós-graduação em Jornalismo ganha com a não obrigatoriedade do diploma para o exercício profissional em jornalismo.

No entanto, antes de adentrar nessa discussão em si, é preciso apresentar uma breve contextualização dos períodos que antecedem a perda da obrigatoriedade do diploma para os jornalistas, para que se possa entender como a situação atual se configurou ao longo do movimento histórico da sociedade brasileira.

Muitas foram as discussões organizadas por entidades representativas da área, que já demonstravam uma grande preocupação com o ensino de graduação, este com influência direta na e da pósgraduação, por meio de uma ação reflexiva. Cita-se, como exemplo, 
um grupo composto pelas organizações mais representativas do setor da comunicação: a Executiva Nacional dos Estudantes de Comunicação Social (Enecos); a Associação Brasileira de Escolas de Comunicação (Abecom); a Sociedade Brasileira de Estudos Interdisciplinares de Comunicação (Intercom); e a Associação Nacional de Programas de PósGraduação em Comunicação (Compós), que, em 2006, fundou o Programa Nacional de Estímulo à Qualidade de Ensino de Jornalismo.

O programa, que objetiva a formulação de políticas educacionais que proporcionem uma aproximação entre a academia e o mercado de trabalho, também pontua as incoerências entre as regulamentações da profissão e os documentos que norteiam o ensino de Jornalismo. Da mesma forma, a Federação Nacional dos Jornalistas (Fenaj) empreendeu muitas iniciativas na discussão de melhores práticas pedagógicas para o ensino de jornalismo e em defesa do estágio supervisionado, proibido durante décadas para estudantes da área. Ressalta-se que, nas novas Diretrizes Curriculares Nacionais (DCN), agora específicas para o curso de Jornalismo, o estágio passou a ser obrigatório, apesar das manifestações contrárias de várias entidades representativas da área.

A Fenaj seguiu um exemplo já posto em prática anteriormente por sindicatos de vários estados. De acordo com Silva (2007), os sindicatos dos jornalistas, no passado, tiveram uma imensa importância na regulamentação profissional, pois influíram diretamente no DecretoLei $n^{\circ} 972$ (que fixou a exigência do diploma em Jornalismo, criou a figura do jornalista provisionado - aquele que não tinha o diploma, mas já exercia a profissão -, permitiu registro especial para o colaborador e incluiu o estágio curricular obrigatório para acadêmicos do último ano), no que se refere ao senso de profissionalismo adquirido pelos jornalistas na década de 1980.

Os sindicatos conseguiram, com a obrigatoriedade do diploma para o exercício profissional, criar uma identidade para o jornalista durante a década de 1980, legitimando sua postura em defesa de tal exigência. O discurso classista, mantido pelos sindicatos dos jornalistas, foi um instrumento de unificação entre os diversos setores da comunicação. Além disso, serviu como álibi para que as instituições 
deixassem à margem dos debates os aspectos substantivos sobre a direção que a prática jornalística estava ganhando com as novas rotinas de produção da notícia e com a invasão das assessorias de comunicação e das agências internacionais de notícias.

Embutiu ainda nessa retórica o caráter elitista na defesa do diploma superior que pretendia consolidar o jornalismo como uma prática social, cuja vocação se destinava à classe média. Concomitantemente à dinâmica estabelecida no campo sindical, a academia vivia um debate acerca dos currículos que deveriam nortear os cursos de Comunicação Social. Nessa direção, as discussões referendaram o modelo das habilitações que integrariam a grande área da Comunicação. A retórica era a de que o modelo curricular deveria acompanhar a divisão social do trabalho da sociedade capitalista.

A questão que se torna corrente hoje é: quem é o jornalista da atualidade? Ele não tem mais a identidade legitimada pelo diploma, não é oriundo apenas dos cursos de Comunicação Social com habilitação em Jornalismo e nem ao menos precisa de um diploma superior para exercer a profissão. As habilitações em Jornalismo estão, a cada ano, mais vazias. Todavia, como a decisão da não obrigatoriedade do diploma para o exercício do jornalismo ainda é relativamente nova (cerca de quatro anos apenas de vigência), a maioria dos profissionais em atuação no mercado de trabalho atualmente ainda teve sua formação na graduação ou, então, é de jornalistas mais antigos, frutos de experiência profissional considerável que lhes rendeu um registro de jornalista provisionado.

O que se reflete neste momento é a constatação de que não há uma base de formação para as futuras gerações de jornalistas. Quais serão os seus modelos? Qual será o seu Código de Ética? Sua história? Sua identidade? Entende-se que a pós-graduação, seja ela lato sensu, seja ela stricto sensu, poderá exercer um papel fundamental na qualificação profissional do novo jornalista que se avistará, sobretudo aquele cuja formação acadêmica na graduação se distancie das ciências sociais.

Sólida formação política, cultural e sociológica é de fundamental importância para o profissional do Jornalismo, e essa base não é parte 
do currículo de vários cursos das áreas das Ciências Exatas e Biológicas. Como disse o presidente da Fenaj na ocasião,

[...] para ser jornalista, é preciso bem mais do que talento no trato com as palavras. É preciso ter um conhecimento amplo sobre cultura e legislação; uma formação sólida sobre os valores éticos que fundamentam a vida em sociedade e que consolidam as conquistas da civilização; o conhecimento das regras deontológicas da profissão, como, por exemplo, ouvir sempre as várias partes interessadas em uma disputa; uma disciplina quase que doentia para checar as informações antes de divulgá-las. Além disso, é preciso que o profissional adquira conhecimentos técnicos, necessários para entrevistar, reportar, editar e pesquisar os assuntos mais variados. Mas, para ser um batalhador da verdade, é preciso tudo isso e mais um pouco. O jornalista precisa ter condições de olhar criticamente os processos sociais, inclusive os meios de comunicação de massa. Isso permite que o profissional veja sempre de vários ângulos as questões que estão sendo tratadas e não embarque, ingenuamente, na primeira versão. O curso de Jornalismo deve servir para cultivar esses valores e essas práticas nos jovens que pretendem trabalhar na profissão. Essas são as exigências para a formação do jornalista, e são importantes para que a população receba uma informação de qualidade (GHEDINI, 2002, p. 44).

\section{A base veio da graduação}

O professor dos cursos de Comunicação Social na atualidade, mesmo depois de concluir uma pós-graduação, teve suas bases teóricas acerca da profissão originadas na sua graduação. Logicamente, essa formação será complementada por meio de cursos de pósgraduação, de experiências profissionais, de pesquisas e de leituras, todavia a base para que possa futuramente optar pela docência Ihe foi ofertada na graduação. Entretanto, com essa graduação esvaziada e com os jornalistas sendo formados nas mais distintas áreas do conhecimento, entende-se que somente a pós-graduação poderia criar uma massa crítica de futuros jornalistas. Não se pode ficar à mercê dos interesses da imprensa capitalista, que quer formar profissionais que sejam meros reprodutores das suas práticas de forma acrítica e sem o sentimento de emancipação que oferta possibilidade para práticas alternativas. 
Não se pode permitir a perda total da base teórica e deixar que o conhecimento especializado acabe por formar profissionais acríticos com relação à mídia e ao jornalismo atual. A formação docente tem de ser refletida no sentido de qualificar melhor os professores. Se a graduação não permite essa qualificação, os cursos de pós-graduação devem suprir essa deficiência.

Esse argumento ainda poderá permanecer válido mesmo com a retomada da obrigatoriedade do diploma para o exercício profissional, visto que os currículos das escolas de Jornalismo ainda estão bastante defasados e presos ao currículo mínimo, como conferem Bernardo e Leão (2012).

Todavia, não apenas a formação do docente dos cursos de Jornalismo constitui um ponto a ser refletido. Ao longo de toda a história do ensino de Jornalismo no Brasil, pode-se observar que muitas são as preocupações concernentes aos cursos de Comunicação Social, e essas preocupações mudam de acordo com os contextos políticos e econômicos em que se constituem os meios de comunicação, mesmo que o fim seja o mesmo: os interesses da classe dominante.

Tais preocupações e discussões levaram ao estabelecimento de novas Diretrizes Curriculares Nacionais (DCN) específicas para o curso de Jornalismo, o que tem levado a algumas críticas e desaprovações por parte da Associação Nacional dos Programas de Pós-Graduação em Comunicação (Compós) e da Executiva Nacional dos Estudantes de Comunicação Social (Enecos), mas também a muitas aprovações por parte de outras entidades representantes da área, como a Federação Nacional dos Jornalistas (Fenaj), o Fórum Nacional de Professores de Jornalismo (FNPJ) e a Associação Brasileira de Pesquisadores em Jornalismo (SBPJor).

Entre os principais desacordos estão duas defesas incompatíveis e excludentes. Essa dualidade de ideias entre representantes da área está disposta no Parecer CNE/CES n³ 39/2013, item 9, que coloca a posição da Compós como contrária ao estabelecimento de diretrizes curriculares específicas para o Jornalismo e cujo argumento se apoia no 
fato de que tal proposta fragmentaria e limitaria a formação jornalística, pois reflete "pensamento tecnicista e disciplinar, enquanto no resto do mundo centros de pesquisa e pesquisadores tornam-se cada vez menos apegados a rótulos disciplinares e a objetos nitidamente recortados" (BRASIL, 2013).

Ainda de acordo com o parecer, a Compós defende que a relação estabelecida entre Jornalismo, Comunicação e Ciências Sociais Aplicadas, no contexto contemporâneo, prevê ou favorece o comunicador polivalente (BRASIL, 2013). Também se manifesta de forma contrária a Enecos, que afirma que as novas Diretrizes Curriculares para o curso de Jornalismo extinguem a área de Comunicação Social como área de conhecimento.

Por sua vez, contra-argumentam as demais entidades, referendadas pela Comissão de Especialistas, que, conforme descreve o Parecer CNE/CES n 39/2013, impor o curso de Comunicação como modelo único acarretou consequências prejudiciais para a formação universitária. Tal argumento é defendido por diversos autores da área que atribuem ao Centro Internacional de Estudos Superiores de Jornalismo (Ciespal), criado pela UNESCO, a implantação do comunicador polivalente no lugar anteriormente ocupado pelo jornalista, o que acaba criando um abismo entre a formação acadêmica e o mercado de trabalho, gerando um grande distanciamento entre ambas as extremidades da formação, ou seja, entre a teoria e a prática (BERNARDO, 2010; BERNARDO; LEÃO, 2012, 2013; GENRO FILHO, 2007, 2004; MEDITSCH, 2002; MOURA, 2002,2006; SILVA, 1991).

Embora um diagnóstico do ensino de Jornalismo possa parecer fácil se analisado de forma superficial, torna-se muito complexo ao se percorrer os meandros da formação do docente de Jornalismo, suas dificuldades e deficiências. A formação universitária dos jornalistas evidencia alguns indicadores que podem ser os principais componentes das dificuldades enfrentadas pela área no Brasil, componentes esses que variam entre a dicotomia da teoria e a prática; a falta de credibilidade e até o desprezo pelo diploma por parte do mercado de trabalho; currículos incoerentes e a formação não integral em Jornalismo, na medida em 
que a formação em Comunicação Social amplia conteúdos e não foca os objetivos específicos da profissão.

Essa relação entre causa e efeito pode ser constatada no já citado indicador de que o curso de graduação é que forma os seus próprios professores de jornalismo. Apesar do fato de, ainda na década de 1980, a Resolução nº 02/84 do Conselho Federal de Educação prever que os professores das disciplinas específicas deveriam ter no registro profissional três anos de experiência na área de sua habilitação, atualmente, após as Diretrizes Curriculares Nacionais, não há mais essa exigência. Assim, apesar da exigência de pós-graduação para ministrar aulas - o que é uma oportunidade para aperfeiçoar os seus conhecimentos -, os professores, em sua grande maioria, adquirem sua formação na graduação e no mercado de trabalho.

\section{A realidade atual e para onde apontam as tendências}

Atualmente, as novas Diretrizes Curriculares Nacionais para o curso de Jornalismo (homologadas em setembro de 2013), assim como já faziam as DCN para os cursos de Comunicação Social, continuam se omitindo com relação à exigência de experiência profissional na área e do registro profissional como jornalista para ministrar aulas. E, apesar de a legislação exigir do docente do ensino superior, no mínimo, uma formação em cursos de especialização nível lato sensu, o número de graduados em atividades de docência ainda é muito significativo, sobretudo em algumas regiões do País em que não há profissionais com a titulação necessária.

No documento intitulado Sursum Corda, Gomes (apud SCHUCH, 2002) representante da Área de Ciências Sociais Aplicadas I na Capes, em resposta às críticas à avaliação trienal dos programas de pós-graduação em Comunicação, disse:

Nota 11. De fato, há programas na área em que ocorre, mais do que em outros, o fenômeno que poderia ser chamado de deslocamento disciplinar. (...) Que novidade há em consideramos que os fenômenos 
da comunicação midiática e da cultura de massa constituem o objeto próprio da área de conhecimento? Que formamos senão profissionais dos processos técnicos da comunicação (que se estendem numa faixa já consideravelmente extensa que vai desde a comunicação organizacional e em meios alternativos até a comunicação e a cultura de alcance massivo). (...) Uma graduação pouco inseminada e pouco sedimentada pela pós-graduação, cuja cabeça está nas nuvens das ciências humanas e/ ou da linguagem e parece considerar ignóbil ocuparse com os fenômenos e objetos próprios da área de conhecimento que a acolhe. Se a pós-graduação em comunicação não for capaz de produzir conhecimento científico em sua área, quem o fará? Nota 12. No Documento de Área, é dito: No caso da área de comunicação isso tem implicações particularmente sérias por causa de uma longa tradição de programas com parte das áreas de concentração e/ou linhas de pesquisa, da especialização docente, das atividades de formação, da pesquisa, das teses e dissertações ou da produção intelectual dedicada a outras áreas de conhecimento. (...) À cobrança por uma maior adequação à área de conhecimento, esses programas têm historicamente reagido com pelo menos uma das três formas abaixo apresentadas: a) com a proposição de um conceito de comunicação consideravelmente alargado de tal maneira a incluir, mesmo que apenas através de analogias, os fenômenos e objetos de que trata o curso. (...) b) com a reiteração da inexistência de um consenso epistemológico fundado sobre quais seriam os fenômenos e objetos da comunicação. (...) c) com uma variedade de argumentos referidos a epistemologias contemporâneas, normalmente apoiados no louvor indiscutível a práticas científicas designadas por categorias como interdisciplinaridade, transdisciplinaridade, multidisciplinaridade e outras assemelhadas. Estes dois documentos, como também o documento À Comunidade dos Programas de Pós-Graduação em Comunicação deveriam, por sua importância, ser conhecidos e analisados por todos os professores de jornalismo (GOMES apud SCHUCH, 2002, p. 103-104).

Gomes (2001) conclui seu texto esperando que representantes das Ciências da Comunicação acolham uma avaliação que tem como objetivo o amadurecimento do setor e que os valores e perspectivas que estão colocados na mesa se abram para toda a área, sem privilégios ou corporativismos.

As discussões presentes retornam às determinações passadas, nas quais se pode compreender o motivo que levou o Conselho Federal de Educação às exigências para o docente do ensino superior previstas 
na Resolução n02/84, e encontram explicações no contexto social e situacional da profissão na época em que vigorou o currículo mínimo. Houve uma pressão muito forte por parte das instituições de ensino superior, assim como dos professores dos cursos de Jornalismo, para que a formação jornalística fosse focada apenas nas atividades jornalísticas. Muitos defendiam inclusive a criação do curso de Jornalismo autônomo, totalmente desvinculado do curso de Comunicação Social, o que hoje é previsto pelas novas DCN, apesar de o próprio parecer CNE/CES n 39/2013 dizer que é inquestionável o pertencimento do Jornalismo à área da Comunicação.

A pressão tinha como objetivo primordial assegurar um mínimo de especificidade ao curso de Jornalismo, que resultasse em melhor qualidade na formação desse profissional. Essa especificidade é traduzida pelo foco nos objetivos do jornalismo, descartando a necessidade de apreender conteúdos vinculados à comercialização de publicidade e à criação de propagandas, entre outros. Os docentes refletiam na ocasião que apenas a graduação - e até mesmo a pósgraduação - não garantia esse preparo para a atividade docente e que deveria aliar-se a isso a experiência do mercado de trabalho, para que se pudesse superar a dicotomia entre a teoria e a prática.

\section{Considerações finais}

Os docentes que estão formando os jornalistas de hoje tiveram suas bases, como já se viu, nos conteúdos generalistas da Comunicação Social e não do Jornalismo e, ainda, receberam conteúdos teóricos dissociados da prática. Tem-se que recuperar o que já se perdeu com o diploma, e não é com uma postura permanentemente defensiva que se irá consegui-lo. Tem-se que não apenas acolher as críticas, como disse Gomes (2001), mas, principalmente, sair da zona de conforto da área perseguida e passar à proatividade, que poderá encontrar um grande aliado na pós-graduação.

Nesse sentido, os cursos de pós-graduação podem oferecer uma estrutura curricular que propicie uma aproximação entre a academia 
e o mercado de trabalho, não para representar um estreitamento da formação e do conhecimento ao domínio dos meios de produção, mas, sim, objetivando uma abordagem crítica e reflexiva desses meios de produção, para que se possa formar um profissional com um maior nível de consciência crítica sobre sua sujeição à imprensa capitalista e que, a partir daí, tenha condições de criar alternativas para a sua atividade profissional.

Mesmo que seja retomada a obrigatoriedade do diploma, objeto da luta de várias entidades representativas da área, a pós-graduação poderá continuar sendo um importante espaço para os debates críticos acerca do exercício profissional, da formação, dos meios da imprensa capitalista e da sua função social.

Recebido em 02/10/2013

Aprovado em 09/12/2013

\section{Referências}

BATTEZZATI, S. C. C. Vencer a Ruptura entre Teoria e Prática: um desafio para os Cursos de Comunicação Social no Brasil. Sapiens, Curitiba, v. 2, p. 12-26, 2006.

BERNARDO, C. H. C. Educação jornalística: entre a cruz da academia e a espada do mercado. 2010. Tese (Doutorado) - Universidade Federal do Mato Grosso do Sul, Campo Grande, 2010

BERNARDO, C. H. C.; LEÃO, I. B. Análise das matrizes curriculares dos cursos de Comunicação Social com habilitação em Jornalismo no Brasil: um retrato da realidade nacional. Intercom - Revista Brasileira de Ciências da Comunicação, v. 35, n. 1, 2012.

Formação do jornalista contemporâneo: a história de um trabalhador sem diploma. Revista Brasileira de História, v. 33, n. 65, p. 337-358, 2013.

BRASIL. Parecer CNE/CSE n³9/2013. Brasília, DF, 2013. 
. Constituição (1988). Constituição da República Federativa do

Brasil. Brasília, DF: Senado, 1988.

GENRO FILHO, A. Sobre a necessidade de uma teoria do jornalismo. Estudos em Jornalismo e Mídia, v. 1, n. 1, 2007.

GHEDINI, F. Jogo dos sete erros: desmascarando algumas falácias sobre a regulamentação profissional dos jornalistas. In: FENAJ (Org.). Formação Superior em Jornalismo: uma exigência que interessa à sociedade. 2. ed. Florianópolis: Cátedra FENAJ - UFSC, 2002. p. 42-46.

MEDITSCH, E. Crescer para os lados ou crescer para cima: o dilema histórico do campo acadêmico do jornalismo. Disponível em: <http:/ / bocc.ubi.pt/pag/_texto.php?htm/2=meditsch-eduardo-dilemahistorico-jornalismo.html>. Acesso em: set. 2007.

MOURA, C. P. de. 0 curso de Comunicação Social no Brasil: do currículo mínimo às novas diretrizes curriculares. 2002. Tese (Doutorado em Ciências da Comunicação) - Universidade de São Paulo. Porto Alegre: EdiPUCRS, 2002.

- Relações Públicas: a regulamentação para o exercício do relacionamento. In: CONGRESSO BRASILEIRO DE CIÊNCIAS DA COMUNICAÇÃO - INTERCOM 2006, 29., 2006, Brasília. Anais... Brasília, DF: Universidade de Brasília, 2006. v. 1. p. 1-17.

SILVA, C. E. L. 0 adiantado da hora: a influência americana sobre o jornalismo brasileiro. São Paulo: Summus, 1991.

SILVA, M. A. R. da. Jornalistas, prá quê? Militância sindical e o drama da identidade profissional. 2007. Tese (Doutorado) - Programa de Comunicação, Universidade Federal Fluminense, Niterói, Rio de Janeiro, 2007.

SCHUCH, H. A. Adequação do ensino na formação de jornalistas. Revista

Brasileira de Ciências da Comunicação, v. XXV, n. 1, jan./jun. 2002. 


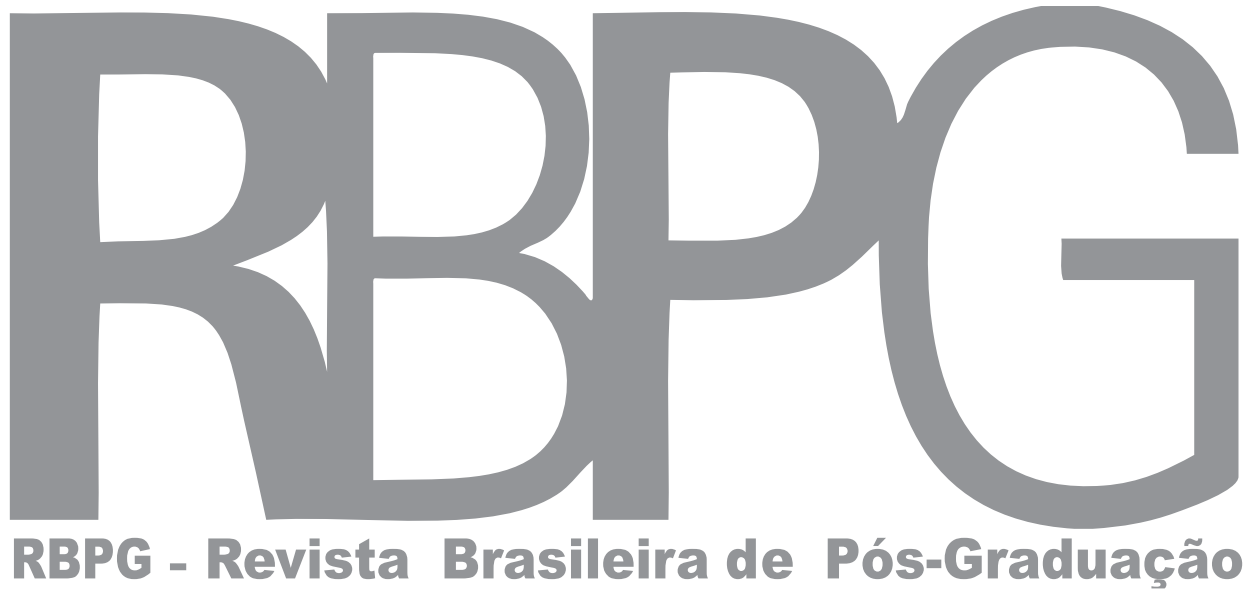

